\title{
EDITORIAL
}

Dieter Merkle • Erdmuthe Raufelder • Petra Jantzen •

Claudia Kehl

\section{Happy 60th birthday to Professor Kienzler!}

Published online: 18 August 2010

(C) Springer-Verlag 2010

Since Reinhold Kienzler took over the duties of an Editor-in-Chief of the "Archive of Applied Mechanics" in the middle of 2004, the journal has seen a formidable growth both in volume and in quality. The recent Impact Factor of almost 1.0 also shows the success of a process of internationalization initiated by the late Horst Lippmann and strongly pushed forward by Friedrich Pfeiffer. This development eventually reaches its final stage under Reinhold Kienzler. It was Professor Pfeiffer who recommended to appoint a successor who will put a stronger focus again on Continuum Mechanics. This target as well was fully achieved by Reinhold Kienzler.

For us Springer employees, it has always been and still is a pleasure to work with Professor Kienzler and his team. We very much like his amiable character and his subtle humor. We wish him all the best for his anniversary and the future. We look forward to many more years of pleasant collaboration.

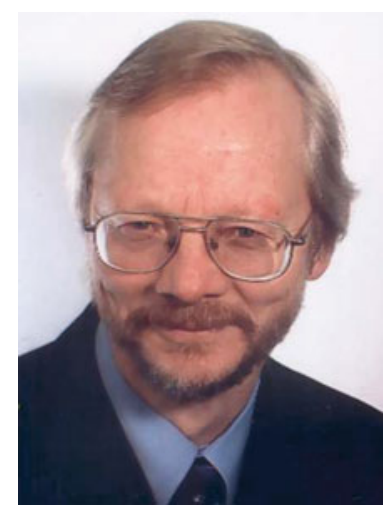

D. Merkle $(\varangle) \cdot$ E. Raufelder · P. Jantzen · C. Kehl

Heidelberg, Germany

E-mail: dieter.merkle@ springer.com 